
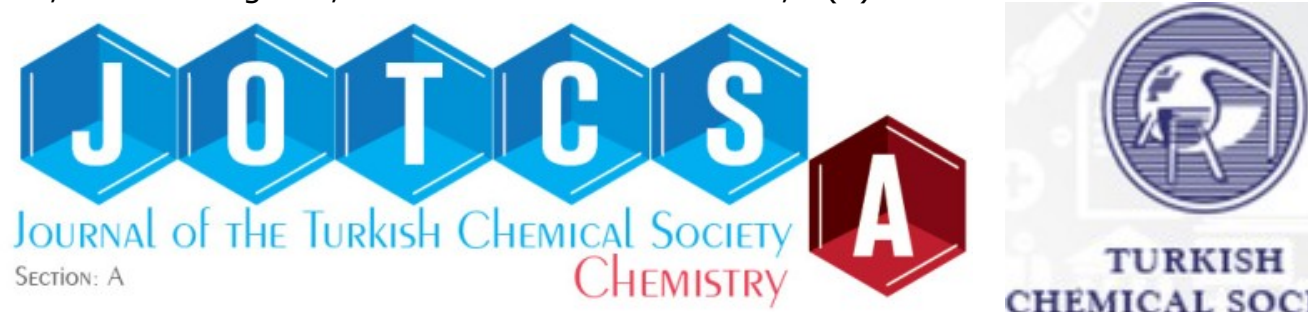

TURKISH CHEMICAL SOCIETY

\title{
Graphene Oxide-Ionic Liquid Used as Solid-Phase Microextraction Coating for Polyphenolic Compounds' Extraction and Determination with GC-MS After On-Fiber Derivatization in Wine
}

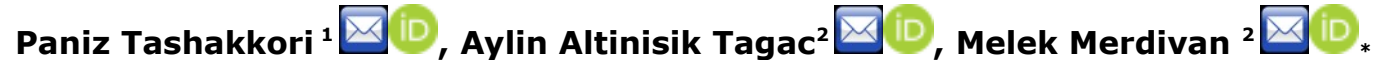 \\ ${ }^{1}$ Graduate School of Natural and Applied Science, Dokuz Eylul University, Tınaztepe Campus, Izmir 35160, \\ Turkey. \\ ${ }^{2}$ Faculty of Science, Chemistry Department, Dokuz Eylul University, Tınaztepe Campus, Izmir 35390, \\ Turkey.
}

\begin{abstract}
We describe the use of a home-made fiber coated by graphene oxide modified by an ionic liquid having methylimidazolium cation with an amino-functional group for the extraction of polyphenolic compounds (P.C.S). We then performed the determination by gas chromatography coupled with mass spectrometry after on-fiber derivatization. The authors optimized the main parameters influencing the extraction and derivatization processes. The on-fiber derivatization was employed within 15 min at $60{ }^{\circ} \mathrm{C}$ using $20 \mu \mathrm{L}$ of trimethylsilyl reagents. Under the optimized conditions, the calibration curves for 12 P.C.S were linear from 0.1 to $1000 \mu \mathrm{g} / \mathrm{L}$, and the detection limits were between 0.02 and $0.1 \mu \mathrm{g} / \mathrm{L}$. We determined the single fiber repeatability obtained for all calibration points and the fiber to fiber reproducibility for $100 \mu \mathrm{g} / \mathrm{L}$ to be $<14.82 \%$ and $<5.87 \%$, respectively. The extraction efficacy of the home-made fiber due to high intermolecular and electrostatic attractions was much better than the commercial fibers. We successfully applied the method to the analysis of P.C.S in wine samples with the recoveries from 72.8 to $99.9 \%$.
\end{abstract}

Keywords: GO-[APMIM][NTf2] coated fiber, SPME-GC-MS, polyphenolic compounds, derivatization onfiber, wine samples.

Submitted: November 29, 2019. Accepted: April 12, 2020.

Cite this: Tashakkori P, Altinisik Tagac A, Merdivan M. Graphene Oxide-Ionic Liquid Used as Solid-Phase Microextraction Coating for Polyphenolic Compounds' Extraction and Determination with GC-MS After OnFiber Derivatization in Wine. JOTCSA. 2020 Apr;7(2):411-26.

DOI: https://doi.org/10.18596/jotcsa.652794.

*Corresponding author: E-mail: melek.merdivan@deu.edu.tr. Phone: +902323018693.

\section{INTRODUCTION}

Polyphenolic compounds (P.C.S) are involved in color formation in plants, and plants can also synthesize some new polyphenolic compounds to protect against pathogens in stress situations (1). Polyphenolic compounds are essential in terms of their positive effects on human health. Their antimutagenic, anticarcinogenic, antioxidant, antiinflammatory, antiallergic, and antipathogenic properties are reported $(2,3)$. Wine is a significant natural antioxidant source when compared to other alcoholic beverages (4).
Because of the complexity of the sample matrix, literature mentions of sample pretreatment techniques, including liquid-liquid extraction (LLE), solid-phase extraction (SPE), stir bar sorptive extraction (SBSE), and solid-phase microextraction (SPME) before their chromatographic detection for extraction and preconcentration of polyphenolic compounds in wine samples (5-8). SPME, an equilibrium-based sample pretreatment technique, provides a single-step analysis by integrating sampling, extraction, preconcentration, and sample introduction for the target analytes. The main advantages of SPME are fast mass transfer, its solvent-free, and simple nature, and lower sample volume (9). Enrichment of organic compounds from 
Tashakkori P, Altinisik Tagac A, Merdivan M. JOTCSA. different kinds of sample matrices is essential, and so new coatings must be developed on fibers for SPME. Literature suggests the orientation of the preparation of new coating materials to the selectivity performance to target analytes as well as the development of more durable, firmer, and highly consistent supports (10).

Graphene oxide (G.O.) obtained by oxidation of epoxy (C-O-C), hydroxyl $(\mathrm{C}-\mathrm{OH})$, carbonyl $(\mathrm{C}=\mathrm{O})$ and carboxylic acid $(\mathrm{COOH})$ groups from basal and surface corners of a single graphite layer has excellent properties such as large surface area, excellent structure, and good chemical stability (11). Recently, graphene oxide-based materials have been progressed and used as coating materials in the sample preparation technique such as SPME, SPE because of its facile functionalization $(12,13)$. Ionic liquids (I.L.S), being potential environmentally friendly solvents, have a great attraction in separation science due to low volatility, high viscosity, excellent thermal stability, and high polarities (14). Besides, its use as stationary phase in liquid chromatography, gas chromatography, and capillary chromatography, and extraction material in micro liquid extraction techniques, I.L.S have been preferred in SPE and SPME as sorbent and coating material both alone and grafted on different supports such as graphene oxide and carbon nanotubes to improve extraction efficiency and stability (15-18).

So far, liquid chromatography-diode array detector (LC-DAD) and liquid chromatography-mass spectrometry (LC-MS) techniques have been reliable solutions for the determination of P.C.S. However, rarely has gas chromatography-mass spectrometry (GC-MS) been preferred due to the need for derivatization for polar P.C.S. In the literature, direct methods $(19,20)$, solid supported-LLE (SS-LLE) (5), SPE method using molecularly imprinted polymers (6), and SPME method using commercial polyalcoholic fiber (P.A.) (8) are available. Along with them, application of carbowax-templated resin (CW/TPR) (21), polystyrene-divinylbenzenepolyacrylonitrile (PS-DVB-PAN) coated fiber (22), and poly(ionic liquid)-based molecularly imprinted polymer (PIL-MIP)-coated fiber (23) before L.C. to wine, fruit juices, and beer samples. Many extraction techniques including LLE (24), liquidliquid microextraction (LLME) (25), SPE using Oasis MAX cartridges (26), SPSE using polydimethylsiloxane (PDMS) coated stir bar (27), SPME with P.A. fiber (28- 30) are present for the determination of P.C.S in wine, fruit juice, and medicinal plant samples before GC-MS/FID or multidimensional GC-MS techniques. Despite the most probable preference of L.C. methods, G.C. can also be a choice for the determination of P.C.S in a complex sample matrix. GC-MS technique has some advantages such as better chromatographic separation using a capillary column, improved detectability, lower matrix effects, more accurate
$2020 ; 7(2): 411-426$

RESEARCH ARTICLE

result, cost-effectiveness, and a more straightforward interface concerning LC-MS.

References concerning the SPME-GC-MS method using only commercial fibers are available for some polyphenolic compounds such as resveratrol, gallic acid, caffeic acid, p-coumaric acid, ferulic acid, syringic acid, and protocatechuic acid (28-30). SPME fibers coated with graphene oxide modified with ionic liquids having vinyl- and benzylimidazolium by sol-gel technique have been performed and used for extraction and determination of phthalate esters and polyaromatic hydrocarbons in water and coffee samples in our previous studies $(18,32)$. In this work, the extraction performance of coating possessing graphene oxide modified with aminoterminated methylimidazolium cation was evaluated for the analysis of twelve P.C.s (syringic acid, protocatechuic acid, cinnamic acid, p-coumaric acid, sinapinic acid, ferulic acid, caffeic acid, quercetin, kaempferol, chlorogenic acid, resveratrol, and gallic acid) in wine using direct immersion-SPME coupled with GC-MS. The graphene oxide-(1-(3aminopropyl)-3-methylimidazolium

bis(trifluoromethylsulfonyl)imide)

(GO-[APMIM] $\left[\mathrm{NTf}_{2}\right]$ ) coated fiber was prepared with layer by layer coating technique onto the surface of stainless steel wire using a crosslinker agent. We performed the derivatization of P.C.S using trimethylsilyl (TMS) reagents on the fiber. The authors compared the efficiency of GO-[APMIM][NTf $\left.f_{2}\right]$ coated fiber with commercial fibers and G.O. coated fiber. Finally, we applied the optimized SPME method for the determination of P.C.S in real white, red, and fruit wine samples.

\section{MATERIALS AND METHODS}

\section{Chemicals and Materials}

We procured the P.C. standards (caffeic acid, gallic acid, quercetin, kaempferol, chlorogenic acid, resveratrol, syringic acid, protocatechuic acid, cinnamic acid, p-coumaric acid, sinapinic acid, and ferulic acid) from Alfa Aesar (Karlsruhe, Germany). We also purchased ethyltrimethylsilane (ETMS), $\mathrm{N}, \mathrm{O}$-bis(trimethylsilyl) trifluoroacetamide (BSTFA), and trimethylchlorosilane (TMCS) as derivatization compounds from the same vendor. 1Methylimidazole, 3-bromopropylamine hydrobromide, bis(trifluoromethane) sulfonimide lithium (LiNTf2), and graphene oxide (2 mg/ $\mathrm{mL}$, dispersion in water) were obtained from SigmaAldrich (St. Louis,USA). We purchased the modified dihydroxyethylene urea as a cross-linking from Hunstman (Utah, USA). All other used reagents were of analytical reagent grade. Deionized water was obtained from a Milli-Q water purification system (Millipore, Bedford, USA). We procured a manual SPME holder, amber glass vials (20 mL) with screw caps and polytetrafluoroethylene/ silicone septa, and polyacrylate (PA, $85 \mu \mathrm{m})$, divinylbenzene/carboxen/polydimethylsiloxane
$50 / 30$
$\mu \mathrm{m})$, 
Tashakkori P, Altinisik Tagac A, Merdivan M. JOTCSA. 2020; 7(2): 411- 426.

RESEARCH ARTICLE carboxen/polydimethylsiloxane (CAR/PDMS, $85 \mu \mathrm{m}$ ) and carbowax/ polyethylene glycol (CW/PEG, 60 $\mu \mathrm{m})$ fibers from Supelco (Bellefonte, USA). Using a $5 \mu \mathrm{L}$ microsyringe from Hamilton (Reno, USA), we produced the SMPE fibers and obtained a stainless steel wire having O.D. $150 \mu \mathrm{m}$ from a local market (Istanbul, Turkey).

Stock standard solution of $1000 \mathrm{mg} / \mathrm{L}$ of each P.C.S was prepared using methanol and stored at $-18^{\circ} \mathrm{C}$. The intermediate solution of the mixture standard of P.C.s was prepared at $200 \mathrm{mg} / \mathrm{L}$ in methanol and stored at $4{ }^{\circ} \mathrm{C}$. We prepared the $\mathrm{pH} 8$ buffer solution using $1 \mathrm{M}$ tris(hydroxymethyl)aminomethane hydrochloride (Tris- $\mathrm{HCl}$ ).

The analyzed samples, including red wine, white wine, and fruit wines, were purchased from local supermarkets in Izmir. The alcohol content was in the range of $12 \%-13.8 \%$ for the studied wines. The bottles of wine were stored at $4{ }^{\circ} \mathrm{C}$ and protected from light before analysis. The authors prepared synthetic wine solutions including $12 \%(\mathrm{v} / \mathrm{v})$ of ethanol with $\mathrm{pH}$ adjusted to 3.5 by tartaric acid for optimization and performance evaluation of the DISPME method.

\section{Instrumentation}

We performed the G.C. analysis on a Trace 1300 gas chromatograph QP2010 equipped with an ISQ QD single quadrupole mass spectrometer and split/splitless injector (Thermo Scientific, USA). A TG-5MS fused silica capillary column $(30.0 \mathrm{~m} \times$ $0.25 \mathrm{~mm}$ I.D., $0.25 \mu \mathrm{m}$ film thickness) supplied from Thermo Scientific (West Palm Beach, FL, USA) was used. High purity helium was employed as the carrier gas, at a flow rate of $1.2 \mathrm{~mL}$ min-1. We employed the following separation temperature program in G.C. for TMS derivatives: initially oven temperature held at $80{ }^{\circ} \mathrm{C}$ for $3 \mathrm{~min}$, then programmed at $10 \circ \mathrm{C}$ min-1 to $220 \circ \mathrm{C}$ (held for 4 min), finally increased to $280{ }^{\circ} \mathrm{C}$ at $20^{\circ} \mathrm{C}$ min-1 (held for $2 \mathrm{~min}$ ). The injection port temperature was at $250{ }^{\circ} \mathrm{C}$ for GO-[APMIM][NTf2] coated SPME fiber. We carried out all injections on the splitless mode for $5 \mathrm{~min}$. After each analysis, we heated all fibers at a desorption temperature for $5 \mathrm{~min}$ in the extra G.C. injection port to prevent carry-over effects. The authors operated the MS in the electron impact

(E.I.) at $70 \mathrm{eV}$ under selected ion monitoring mode (SIM) by monitoring two relevant $\mathrm{m} / \mathrm{z}$ fragments for TMS derivatives given in Table S1. The GC-MS ion source and interface were set at $250{ }^{\circ} \mathrm{C}$ and $280^{\circ} \mathrm{C}$, respectively. Figure 1 gives the chromatogram of P.C.S and their M.S. spectra.

The Fourier transform infrared (FTIR) spectra of G.O. and GO-[APMIM][NTf2] were obtained by using a Thermo Fisher Scientific Nicolet iS10 model FTIR Spectrometer. We employed thermogravimetric analysis (TGA) for investigation of their thermal properties. The TGA was performed between 30 and $450{ }^{\circ} \mathrm{C}$ at a rate of $10^{\circ} \mathrm{C} / \mathrm{min}$ under a nitrogen atmosphere with a Perkin-Elmer Diamond TG/DTA instrument. X-ray Diffractometer measurements were made by a Philips X'Pert PROBE model with a monochromatic Cu-Ka X-ray source at $2 \theta=10-60^{\circ}$. The authors evaluated the surface morphology GO[APMIM][NTf2] coated fiber with scanning electron microscopy (SEM, Carl Zeiss 300VP, Jena, Germany).

\section{Derivatization Procedure}

By on-fiber derivatization process, the fibers after SPME firstly were inserted into a flask, dried under nitrogen atmosphere for $5 \mathrm{~min}$ and then transferred into the headspace of a $1.5 \mathrm{~mL}$ glass vial containing $20 \mu \mathrm{L}$ of BSTFA: TMCS $(9: 1, \mathrm{v}: \mathrm{v})$ solution and held at $60{ }^{\circ} \mathrm{C}$ for $15 \mathrm{~min}$.

\section{Preparation of the Fiber}

After etching of stainless steel wire as previously described (18), the tip of wire was dipped into dihydroxyethylene urea cross-linking reagent for 1 $h$, then inserted into G.O. dispersion in water for 30 min. These steps were repeated for three times for efficient coating. We dipped the G.O. coated fiber vertically into the $0.02 \mathrm{~g}$ [APMIM][NTf2], which was synthesized according to the previous methods given in the literature $(18,33)$, in $5 \mathrm{~mL}$ of methanol for $2 \mathrm{~h}$ at room temperature. This step was repeated in sextuplicate to increase the thickness of the fiber coating. Then, the home-made fiber prepared was dried at room temperature overnight and conditioned in sextuplicate in the injection port of G.C. at $250{ }^{\circ} \mathrm{C}$ for 5 min under nitrogen atmosphere. 


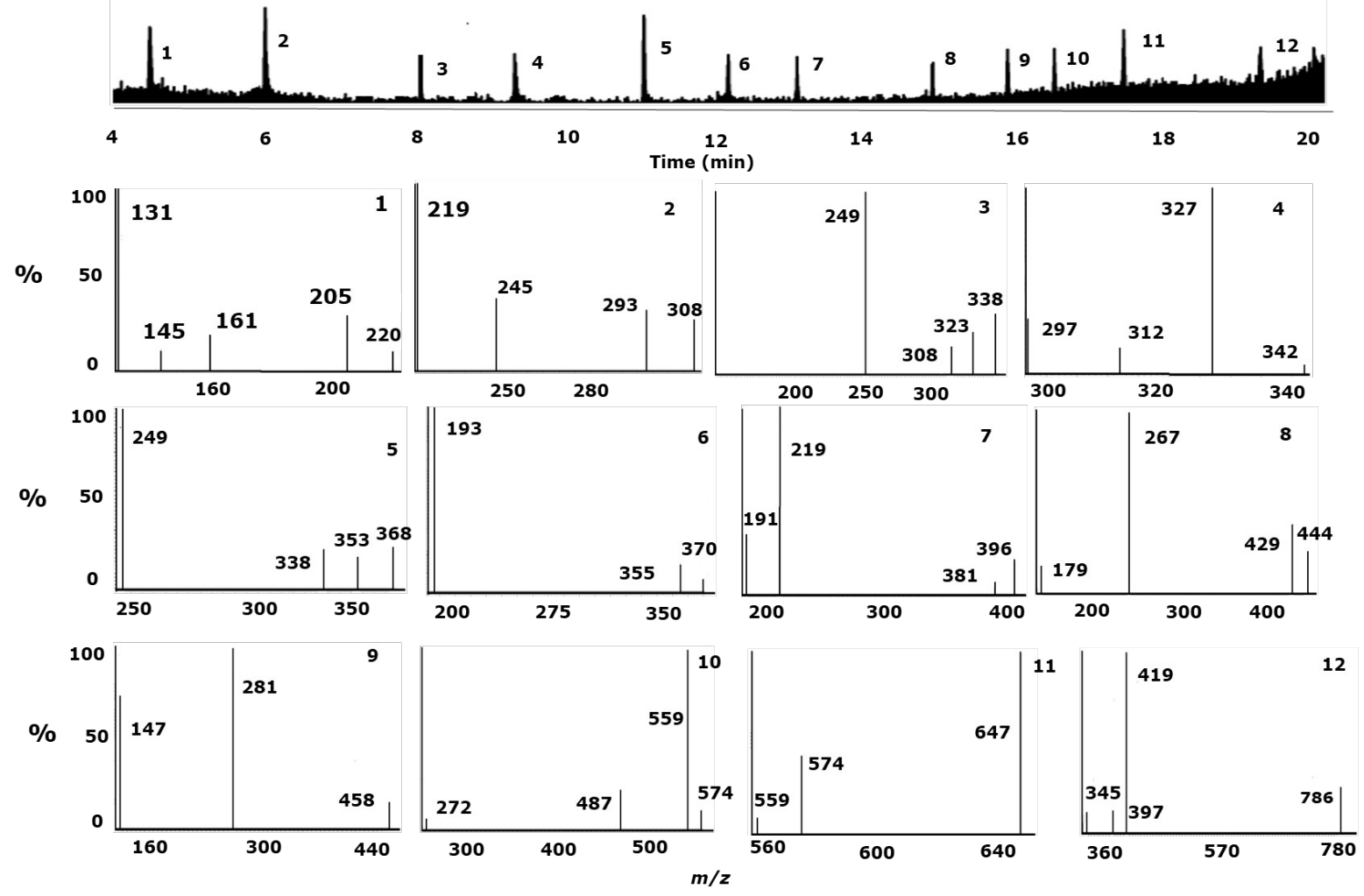

Figure 1. Chromatogram of P.C.s standards and M.S. spectra of P.C.s by the proposed method. Peak identification: (1) cinnamic acid, (2) p-coumaric acid, (3) ferulic acid, (4) syringic acid, (5) sinapinic acid, (6) protocatechuic acid, (7) caffeic acid, (8) resveratrol, (9) gallic acid, (10) kaempferol, (11) quercetin, (12) chlorogenic acid.

The characterization results of GO-[APMIM][NTf2] coating material by FTIR, XRD and T.G. were shown in Figure S1. FTIR (cm-1): 2914, 1847, 1578, and 1456. $\operatorname{XRD}(2 \theta)=23.67^{\circ}, 38.17^{\circ}$ and $40.51^{\circ}$. TG $\left(25-450^{\circ} \mathrm{C}\right)$ : from $100 \%$ to $70 \%$ weight loss.

\section{DI-SPME Procedure for Analysis of P.C.S}

Firstly, synthetic wine or wine sample solution was prepared by adjusting $\mathrm{pH}$ to 8 and placed into a 20$\mathrm{mL}$ amber glass vial. The vial was placed in a metallic block on a magnetic heater. After equilibration for $5 \mathrm{~min}$, the $1 \mathrm{~cm}$ tip of the GO[APMIM][NTf2] coated SPME fiber was exposed to the test solution at adjusted temperature for a particular time while stirring at $400 \mathrm{rpm}$ using a stirring bar. Extractions were performed using a metallic block and a heater with a magnetic stirrer. After extraction, the fiber was dried under a nitrogen stream for $5 \mathrm{~min}$, derivatized by BSTFA:TMCS mixture, and inserted into GC-MS for analyzing P.C.s. Because of the complex composition of wine, we have used two home-made fibers prepared in the extraction experiments. Using one prepared GO-[APMIM][NTf2] coated fiber, we were successful to perform 150 injections with no remarkable decrease in recovery and repeatability.

\section{RESULTS AND DISCUSSION}

\section{Optimization of the Derivatization Process}

G.C. analysis needs a derivatization procedure for hydroxyl functional groups. The most commonly used derivatization reagents are TMS reagents containing $\mathrm{N}-$ methyl-N(trimethylsilyl)trifluoroacetamide), N-methyl-N-tertbutyldimethylsilyl-trifluoroacetamide, BSTFA and TMCS for derivatization of polyphenolic compounds and their metabolites $(25,28,34,35)$. TMS reagents are hydrolyzed in aqueous solutions. Because of this, the SPME fiber after extraction was dried under nitrogen atmosphere. Therefore, drying time for fiber after extraction, suitable derivatizing reagent and volume, and time and temperature of derivatization were investigated. The optimal conditions to get the highest signal came to an agreement at $60{ }^{\circ} \mathrm{C}$ for $15 \mathrm{~min}$ using $20 \mu \mathrm{L}$ of BSTFA: TMCS (9:1) after drying the fiber for 5 min under nitrogen gas for all P.C.s studied following the extraction.

\section{Optimization of the SPME Conditions}

SPME experimental conditions such as sample $\mathrm{pH}$, ionic strength, extraction temperature, and extraction time were investigated to obtain reproducible results with high extraction performance of the GO-[APMIM][NTf2] coated SPME 
Tashakkori P, Altinisik Tagac A, Merdivan M. JOTCSA. fiber for P.C.s by using DI-SPME method. We carried out all the experiments in triplicate using synthetic wine sample solutions containing $100 \mu \mathrm{g} / \mathrm{L}$ P.C.S standard and reported the mean values.

\section{Sample pH and Ionic Strength}

The $\mathrm{pH}$ of a sample solution affects the retention of analytes on the surface of the coating material of SPME fiber. It is possible to observe an interaction between the analyte and the sorbent when the polarities of them are close to each other. The $\mathrm{pH}$ of the sample is adjusted to obtain reproducible extraction efficiency, taking into account the pKa of analytes. Depending on the pKa values of P.C.S, we performed the extraction experiments to control the effect of $\mathrm{pH}$ at $\mathrm{pH} 4$ and 8 . The authors saw that the extraction efficiencies of P.C.s studied were higher at $\mathrm{pH} 8$ except syringic acid and gallic acid (Figure $2 \mathrm{~A})$. The reason is that the P.C.S studied were ionized mainly at $\mathrm{pH} 8$ and the sorption between the ionized P.C.S and imidazolium cation took place by electrostatic interaction. Besides, the aromatic ring and $-\mathrm{O} . \mathrm{H}$., $-\mathrm{OCH} 3$ and $-\mathrm{COOH}$ groups in P.C.S caused dipole-dipole and $\Pi-\Pi$ interactions during the sorption to the surface of GO-[APMIM][NTf2] coated fiber. The time of analysis is optimal at $\mathrm{pH} 8$ and selected for further studies because the peak areas of most P.C.s studied were high at $\mathrm{pH} 8$.

In HS-SPME and rarely in DI-SPME methods, increasing the ionic strength of the aqueous solution improved the peak areas, favoring the extraction of analytes into the fiber and solubility of the extracted compounds. Thus, we investigated the impact of ionic strength on the uptake of P.C.S after exposure to the fiber at three different $\mathrm{NaCl}$ concentrations $(0 \%, 10 \%$, and $25 \%, w / v)$. As seen in Figure $2 \mathrm{~B}$, the addition of $\mathrm{NaCl}$ caused a slight increase in the
RESEARCH ARTICLE
peak areas of P.C.s $(10 \%$, w/v) initially and then led to a more decrease in the extraction efficiency. The presence of a high amount of salt may cause an increase in the viscosity of the solution, which decreases the mass transfer rate and affects the peak areas of P.C.S negatively. So, we used $10 \%$ $\mathrm{NaCl}$ solution as a test for further experiments.

\section{Extraction Temperature and Extraction Time}

Extraction temperature is an essential factor for the extraction efficiency. It influences the mass transfer and affects the extraction time in the SPME method. Therefore, we investigated the effect of extraction temperature on the extraction efficiency of P.C.s by exposing the fiber to the sample solution at 30 and $70{ }^{\circ} \mathrm{C}$ for $30 \mathrm{~min}$. Figure $2 \mathrm{C}$ shows the temperature profiles obtained. The authors achieved the highest extraction efficiency at $30{ }^{\circ} \mathrm{C}$ for all P.C.S. Increasing temperature caused a decline in the peak areas of P.C.S. This event may be explained by that the high temperature causes a rapid motion of neutral or ionized P.C.s but decrease the diffusion of P.C.S on fiber coating due to the exothermic extraction process (36). The researchers performed subsequent experiments at $30^{\circ} \mathrm{C}$ for the homemade fiber because of the maximum extraction efficiency at this temperature.

The extraction time deals with the interaction of analytes in solution and fiber coating in SPME. The extraction time was investigated from 15 to $90 \mathrm{~min}$ at $30{ }^{\circ} \mathrm{C}$ by stirring at $400 \mathrm{rpm}$ to acquire the adsorption equilibrium for P.C.S on the fiber surface. As shown in Figure 2D, the peak areas of all P.C.S reached the maxima in 30 min. Thus, considering the extraction efficacy and the analytical time, 30 min was chosen as the optimized fiber exposure time. 

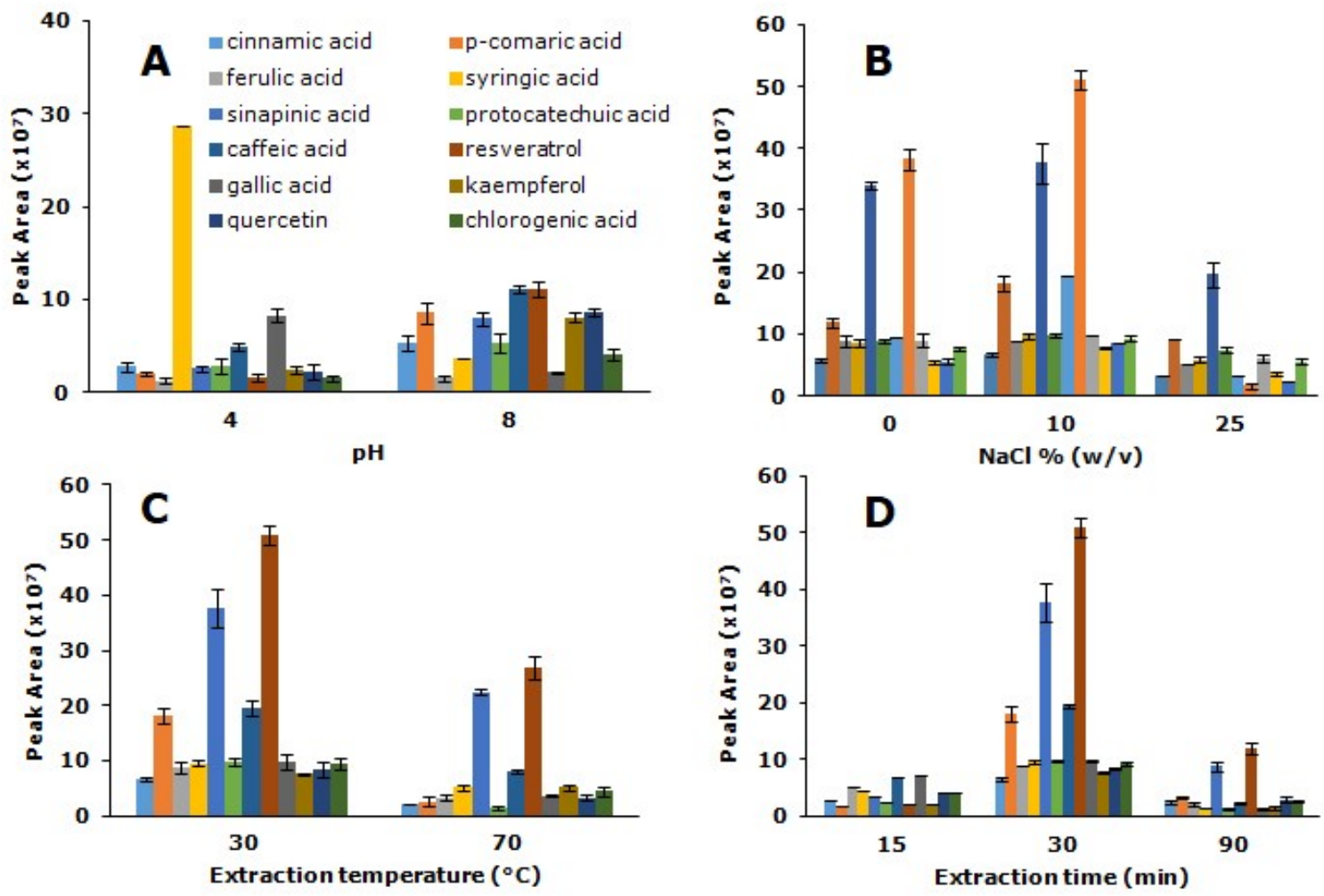

Figure 2. Effects of $\mathrm{pH}$ of sample solution $(\mathrm{A})$, ionic strength $(\mathrm{B})$, extraction temperature $(\mathrm{C})$, and extraction time (D) of GO-[APMIM][NTf2] fiber on the DI-SPME method.

Comparison of Extraction Efficiency of GO[APMIM][NTf ${ }_{2}$ ] Coated Fiber with Commercial Fibers and G.O. Coated Fiber

DI-SPME method was also optimized for P.A., DVB/CAR/PDMS, CAR/PDMS, and CW/ PEG commercial SPME fibers to compare their extraction efficiency with the GO-[APMIM][NTf $\left.{ }_{2}\right]$ coated fiber. These fibers were conditioned on the injection port of G.C. before the extraction experiments at $280^{\circ} \mathrm{C}$, 270, 300, and $240{ }^{\circ} \mathrm{C}$ for P.A., DVB/CAR/PDMS, CAR/PDMS, and CW/ PEG for 30 min according to the manufacturer recommendation, respectively. We carried out the SPME extraction experiments in the range of $15-60 \mathrm{~min}$ with $100 \mu \mathrm{g} / \mathrm{L}$ P.C.s solution at $\mathrm{pH} 8$ and $400 \mathrm{rpm}$ to obtain the optimum extraction time. The authors obtained the highest extraction efficiency as $30 \mathrm{~min}$ for all commercial SPME fibers.
We studied the extraction temperature at 30 and 70 ${ }^{\circ} \mathrm{C}$ at the optimized extraction time. The experimental results indicated that the optimum extraction temperature was $30^{\circ} \mathrm{C}$ for all commercial fibers. Although the optimal extraction parameters of commercial fibers are the same as the GO[APMIM] $\left[\mathrm{NTf}_{2}\right]$ coated fiber, the extraction efficiency of the home-made coated fiber was much higher than those commercial fibers (Figure 3). Within the commercial SPME fibers, the peak areas of cinnamic acid and kaempferol with P.A. fiber and the peak area of cinnamic acid with CW/PEG fiber were only higher than that of the home-made fiber. As seen in Figure 2, the presence of [APMIM][NTf $\left.{ }_{2}\right]$ caused much increase in the extraction efficacy of P.C.S with respect to only G.O. coated fiber. 


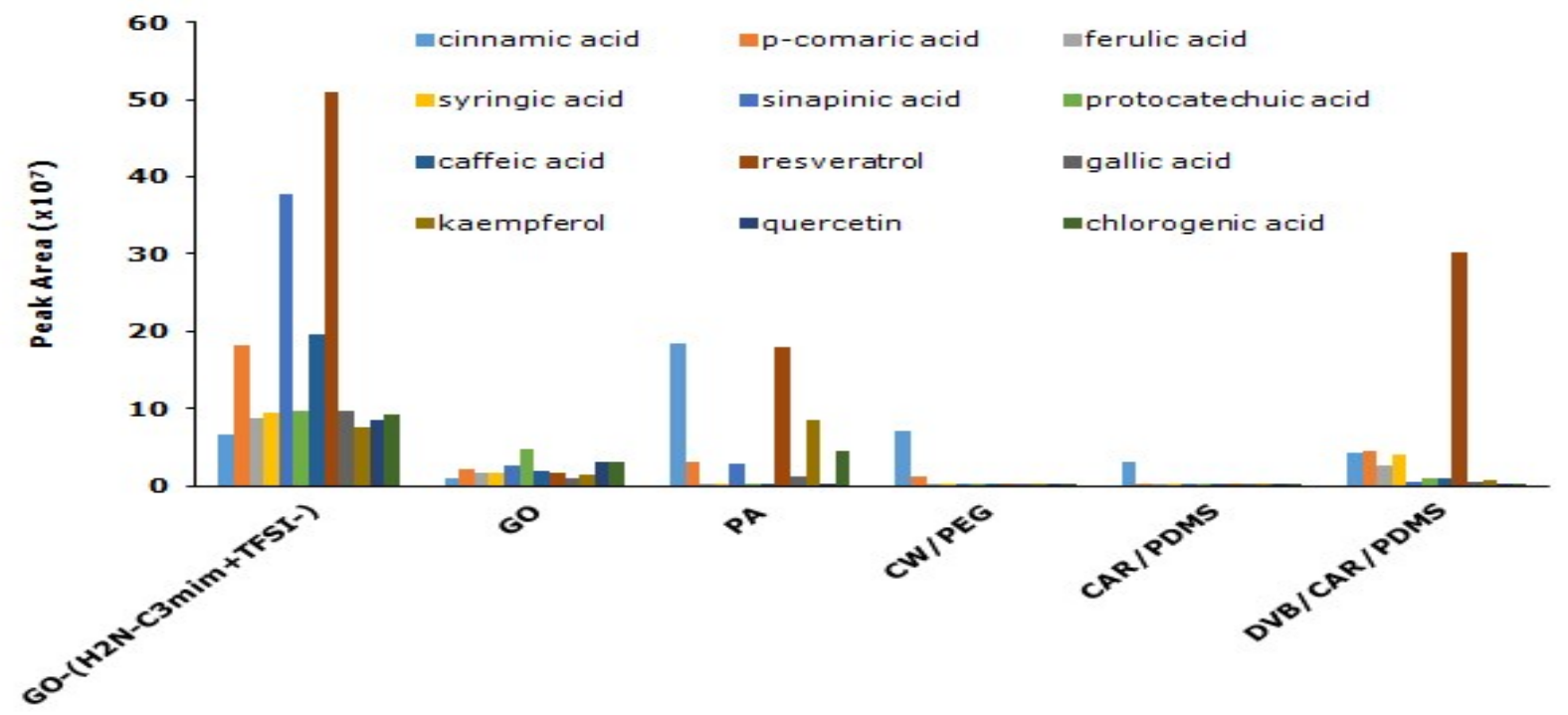

Figure 3. Comparison of the extraction efficiencies of GO-[APMIM][NTf $f_{2}$ coated fiber with G.O. coated and P.A., CAR/PDMS, DVB/CAR/PDMS, and CW/ PEG commercial fibers. Conditions: $\mathrm{C}_{\mathrm{PCS}}=100 \mu \mathrm{g} / \mathrm{L}$; sample $\mathrm{pH}$ $=8$; stirring rate $=400 \mathrm{rpm}$; extraction temperature $=30^{\circ} \mathrm{C}$; extraction time $=30 \mathrm{~min}$.

Table 1. Analytical figures of merit for GO-[APMIM][NTf2] coated fiber in DI-SPME-GC-MS method.

\begin{tabular}{llllll}
\hline PCs & $\begin{array}{l}\text { Linear range } \\
(\mu \mathrm{g} / \mathrm{L})\end{array}$ & $\mathrm{R} 2$ & $\begin{array}{l}\text { LOD } \\
(\mu \mathrm{g} / \mathrm{L})\end{array}$ & $\begin{array}{l}\text { Precision } \\
(\mathrm{RSD}, \%)\end{array}$ & $\begin{array}{l}\text { Fiber-to-Fiber } \\
(\mathrm{RSD}, \%)\end{array}$ \\
\hline Cinnamic acid & $0.1-1000$ & 0.998 & 0.05 & $2.48-11.37$ & 2.39 \\
p-Coumaric acid & $0.25-1000$ & 0.998 & 0.1 & $2.22-9.23$ & 2.79 \\
Ferulic acid & $0.25-1000$ & 0.998 & 0.1 & $2.57-9.68$ & 2.18 \\
Syringic acid & $0.1-1000$ & 0.999 & 0.02 & $1.32-14.82$ & 4.68 \\
Sinapinic acid & $0.1-1000$ & 0.997 & 0.02 & $0.71-13.29$ & 3.04 \\
Protocatechuic acid & $0.1-1000$ & 0.997 & 0.02 & $0.92-8.42$ & 5.71 \\
Caffeic acid & $0.25-1000$ & 0.997 & 0.05 & $3.48-14.74$ & 1.64 \\
Resveratrol & $0.1-1000$ & 0.997 & 0.02 & $0.93-10.53$ & 4.79 \\
Gallic acid & $0.25-1000$ & 0.997 & 0.02 & $0.90-9.85$ & 2.33 \\
Kaempferol & $0.1-1000$ & 0.997 & 0.02 & $0.78-9.85$ & 5.87 \\
Quercetin & $0.1-1000$ & 0.998 & 0.02 & $3.14-9.24$ & 4.06 \\
Chlorogenic acid & $0.1-1000$ & 0.997 & 0.02 & $2.73-11.92$ & 2.25 \\
\hline
\end{tabular}


Table 2. Comparison of the proposed method with previous SPME and other extraction methods for determination of P.C.s studied.

\begin{tabular}{|c|c|c|c|c|c|c|c|c|c|}
\hline & $\begin{array}{l}\text { Coating Material/ } \\
\text { Sorbent }\end{array}$ & $\begin{array}{l}\text { Extraction } \\
\text { type }\end{array}$ & Sample & PCs & $\begin{array}{l}\text { LR } \\
(\mu g / L)\end{array}$ & $\begin{array}{l}\text { LOD } \\
(\mu g / L)\end{array}$ & $\begin{array}{l}\text { RSD } \\
(\%) \\
\end{array}$ & $\begin{array}{l}\text { Recovery } \\
(\%)\end{array}$ & Refs \\
\hline LC-DAD & MIP & SPE & wine & $\begin{array}{l}\text { GA } \\
\text { PrA }\end{array}$ & $\begin{array}{l}10-70 * \\
0.1-4.5\end{array}$ & $\begin{array}{l}0.4^{*} \\
0.1^{*}\end{array}$ & $\begin{array}{l}6.4-8.0 \\
7.0-8.1\end{array}$ & $\begin{array}{l}89.1-98.3 \\
95-100\end{array}$ & (6) \\
\hline GC-MS & & LLME & plasma & $\begin{array}{l}\text { Phenolic } \\
\text { acids }\end{array}$ & $10-5000$ & $0.5-16.9$ & $3.8-18.4$ & $80-110$ & (25) \\
\hline LC-FLD & $\begin{array}{l}\text { PDMS } \\
\text { CW/TPR }\end{array}$ & $\begin{array}{l}\text { SBSE } \\
\text { SPME }\end{array}$ & $\begin{array}{l}\text { Wine, must, } \\
\text { fruit juice }\end{array}$ & $\begin{array}{l}\text { trans-res } \\
\text { trans-res/ } \\
\text { cis-res }\end{array}$ & $\begin{array}{l}0.5-50 \\
5-150 / \\
2-150\end{array}$ & $\begin{array}{l}0.1 \\
2 / 0.5\end{array}$ & $\begin{array}{l}6.9 \\
5.3 / 4.8\end{array}$ & $82-105$ & $(21)$ \\
\hline LC-DAD & PA & SPME & $\begin{array}{l}\text { Wine, spirit, } \\
\text { grape juice }\end{array}$ & res & $0.1-500$ & 0.4 & $6.5-12.6$ & $92.2-99.4$ & (8) \\
\hline GC-MS & PDMS stir bar & SBSE & Wine & $\begin{array}{l}\text { res, } \\
\text { picetannol }\end{array}$ & $0.2-1$ & $0.004-0.015$ & $5-9$ & $79-109$ & (27) \\
\hline GC-MS & PA & SPME & $\begin{array}{l}\text { Wine and } \\
\text { grape }\end{array}$ & res & $1-150$ & 0.09 & 2.4 & $85-116$ & $(28)$ \\
\hline LC-DAD & PIL/MIP & SPME & $\begin{array}{l}\text { Fruit juice } \\
\text { and beer }\end{array}$ & $\begin{array}{l}\text { CA } \\
\text { FA }\end{array}$ & $\begin{array}{l}0.1-200 \\
0.05-200\end{array}$ & $\begin{array}{l}0.019-0.024 \\
0.011-0.042\end{array}$ & $\begin{array}{l}2.3-8.2 \\
4.6-8.0\end{array}$ & $\begin{array}{l}80.1-111 \\
72.1-109\end{array}$ & (23) \\
\hline LC-MS/MS & PS-DVB-PAN & SPME & $\begin{array}{l}\text { Wine, berry, } \\
\text { grape }\end{array}$ & $\begin{array}{l}\mathrm{CA} \\
\text { res }\end{array}$ & $\begin{array}{l}1.5-500 \\
5-500\end{array}$ & $\begin{array}{l}0.5 \\
1.5\end{array}$ & $\begin{array}{l}5 \\
4\end{array}$ & $\begin{array}{l}82 \\
77\end{array}$ & $(22)$ \\
\hline $\begin{array}{l}\text { Multidimensional } \\
\text { GC-MS }\end{array}$ & PA & SPME & Wine & res & $10-5000$ & 7.08 & $3.0-9.2$ & 72.7-94.7 & (29) \\
\hline GC-MS & Oasis MAX & SPE & Wine & trans-res & up to 2500 & 0.24 & 8 & $92.5-108.2$ & $(26)$ \\
\hline GC-FID & PA & SPME & $\begin{array}{l}\text { Synthetic } \\
\text { solution }\end{array}$ & $\begin{array}{l}\text { pCuA, SyA, } \\
\text { PrA, FA, CA, } \\
\text { GA }\end{array}$ & $2.2-354.4$ & $0.01-1.77$ & $9.78-17.89$ & - & $(30)$ \\
\hline GC-MS & GO-[APMIM][NTf2] & SPME & Wine & $\begin{array}{l}\text { CnA, SyA, } \\
\text { SnA, PrA, } \\
\text { Res, Kfl, } \\
\text { Qcn, ChA } \\
\text { pCuA, FA, } \\
\text { CA, GA }\end{array}$ & $\begin{array}{l}0.1-1000 \\
0.25-1000\end{array}$ & $\begin{array}{l}0.02-0.05 \\
0.02-0.1\end{array}$ & $\begin{array}{l}0.78-11.92 \\
0.90-14.74\end{array}$ & $\begin{array}{l}72.8-99.9 \\
80.7-99.8\end{array}$ & This study \\
\hline
\end{tabular}

LC-FLD: Liquid chromatography-fluorescence detector MEPS: Microextraction packed sorbent

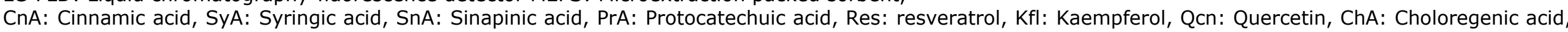
pCuA: p-Coumaric acid, F.A.: Ferulic acid, CA: Caffeic acid, GA: Gallic acid. $* \boldsymbol{\mu g} / \mathbf{m L}$ 


\section{Surface Morphology of GO-[APMIM][NTf2] Coated Fiber}

We characterized the surface morphology of the G.O. and GO-[APMIM][NTf2] material by SEM (Figure 4). In Figure $4 a$, it is evident G.O. sheets seem the sheet-like structure with a smooth surface and wrinkled edge. After a combination with I.L. (Figure 4b), the coating material had a rougher surface, which pointed out that I.L. stacks assembled on the surface of the G.O. layers. The
GO-[APMIM][NTf2] is porous with a much rougher surface, which indicates that the coating material has a large surface area. Figure 4c-d shows that the coating possessed a homogeneous and porous structure. The porous structure of the coating could have increased the available surface area of the fiber, as well as its extraction ability. From the SEM images in Figure $4 c-d$, the coating thickness was determined as $27.5 \mu \mathrm{m}$ for the GO-[APMIM][NTf2] coating material.
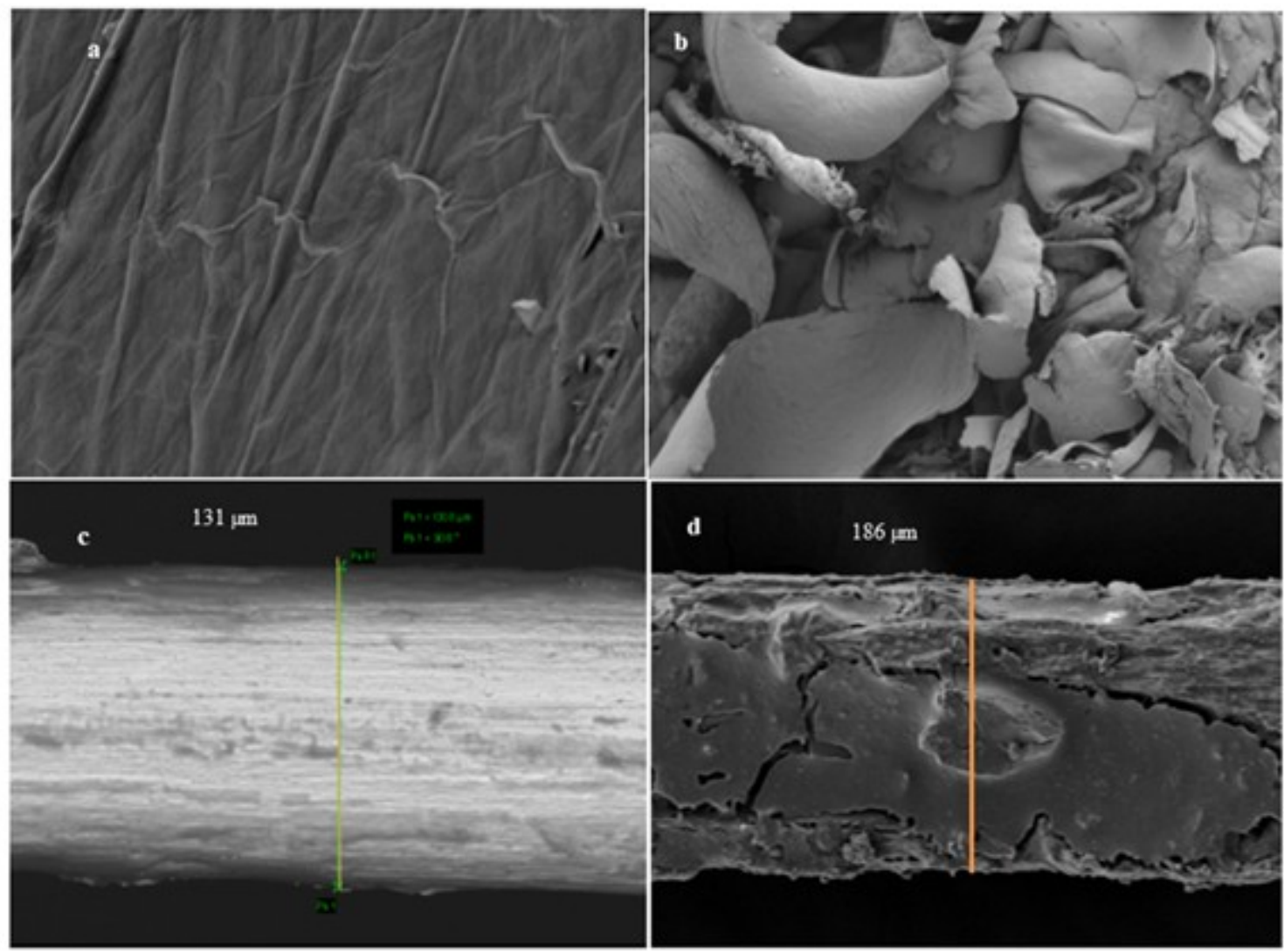

Figure 4. SEM images of GO, $2 \mu \mathrm{m}, 10000 \times(a) ; G O-[A P M I M][N T f 2] 20 \mu \mathrm{m}, 500 \times$ (b); etched stainless steel fiber, $20 \mu \mathrm{m}, 1000$ X (c); GO-[APMIM][NTf2] fiber, $20 \mu \mathrm{m}, 1000$ X (d).

\section{Application to Real Sample Analysis}

The proposed GO-[APMIM][NTf2] coated fiber was used for the analysis of twelve P.C.S in red wine, white wine, and fruit wine samples by DI-SPME-GCMS method (Table 3). By SPME, known as a nonexhaustive method, the amount of analytes found in the sample represents the free concentration of analytes (20). We examined the recoveries of 12 P.C.S by spiking 5 and $200 \mu \mathrm{g} \mathrm{L-1}$ concentration of P.C.S to the wine samples to evaluate the accuracy of the proposed DI-SPME-GC-MS method with the home-made coated fiber. As shown in Table 3, we acquired the recoveries of P.C.S in the range of 75.4- $99.8 \%$ for red wine, $75.2-99.9 \%$ for white wine, and $71.2-99.7 \%$ for fruit wines with the RSDs less than $13.71 \%$ depending on the P.C.S and samples. Figure 5 shows the typical chromatograms of fruit wines, white wine, and red wine samples as blank and red wine spiked of P.C.s standard. 


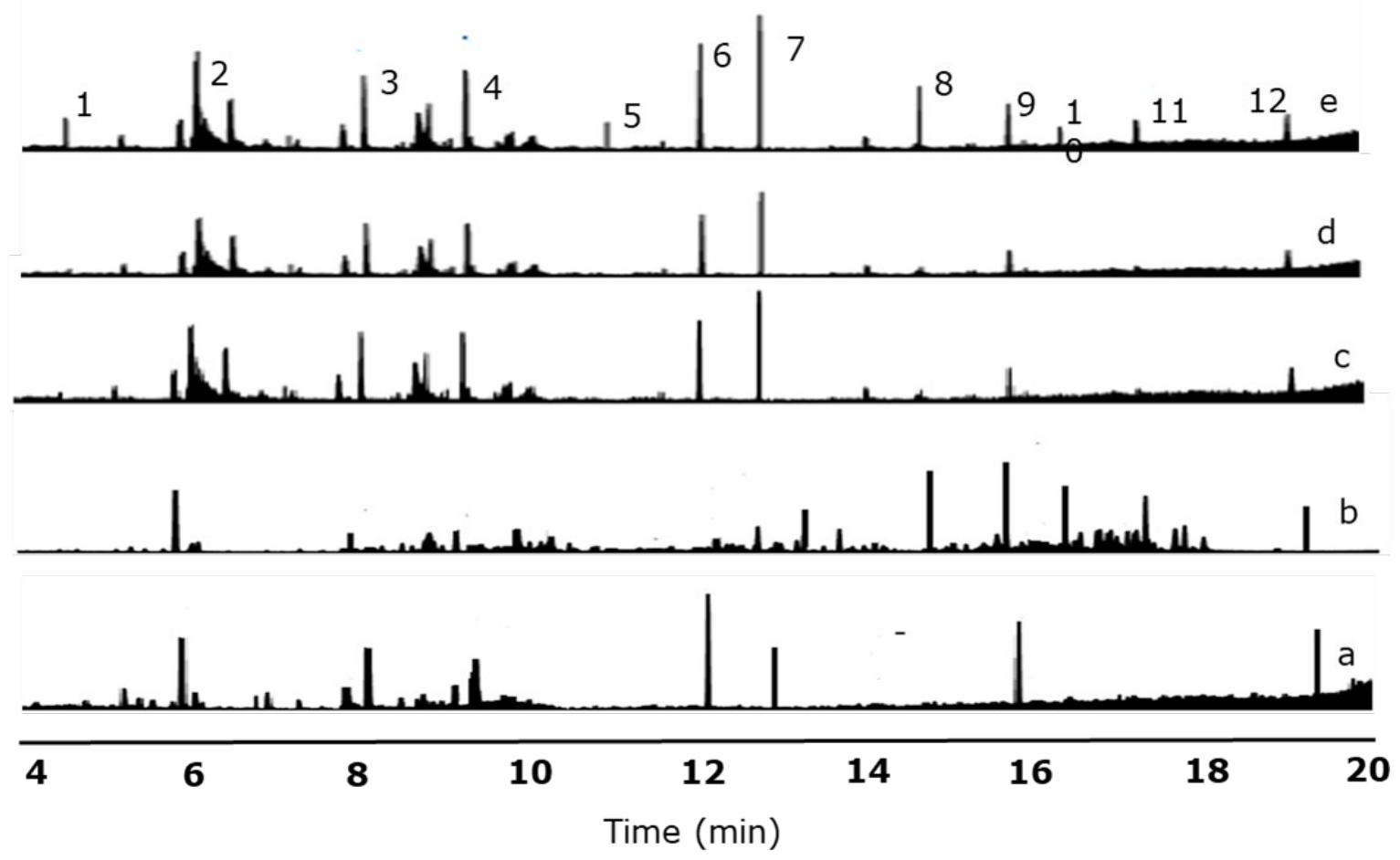

Figure 5. Chromatograms of P.C.s for wine samples by the proposed method. (a) blank melon wine, (b) blank blueberry wine, (c) blank white wine, (d) blank red wine, and (e) blank red wine spiked with P.C.s at $20 \mu \mathrm{g} \mathrm{L-1.} \mathrm{Peak} \mathrm{identification:} \mathrm{(1)} \mathrm{cinnamic} \mathrm{acid,} \mathrm{(2)} \mathrm{p-coumaric} \mathrm{acid,} \mathrm{(3)} \mathrm{ferulic} \mathrm{acid,} \mathrm{(4)} \mathrm{syringic} \mathrm{acid,} \mathrm{(5)}$ sinapinic acid, (6) protocatechuic acid, (7) caffeic acid, (8) resveratrol, (9) gallic acid, (10) kaempferol, (11) quercetin, (12) chlorogenic acid.

\section{CONCLUSION}

The GO-[APMIM][NTf2] coated fiber was prepared and successfully applied for the determination of P.C.S in wine samples by the proposed DI-SPME under optimized conditions ( $30{ }^{\circ} \mathrm{C}, 30 \mathrm{~min}, 5 \mathrm{~min}$ desorption) and on-fiber derivatization (20 min) combined to GC-MS method. The developed homemade fiber exhibits high durability, excellent thermal behavior, high fiber-to-fiber reproducibility, and long term stability without a reduction in the extraction performance after more than 150 extraction cycles. Also, the extraction efficiency of the GO-[APMIM][NTf2] coated fiber was much better than the studied commercial fibers (P.A.,
CAR/PDMS, DVB/CAR/PDMS, and CW/PEG). The prepared fiber presents a wide linear range, low LODs, and excellent repeatability and reproducibility in the determination of the P.C.S in different kinds of wine samples. Besides, by using the home-made SPME fiber, good recoveries for the analysis of P.C.S were succeeded in the wine samples.

The performance of the present coating material could be due to electrostatic interactions between imidazolium cation and the P.C.S, as well as the $\Pi-\Pi$ and dipole-dipole interactions with G.O. and I.L., and the P.C.S. Thus, GO-[APMIM][NTf2] coated fiber can be taken into account as SPME fiber for the extraction of P.C.S in various kinds of food samples. 
Table 3. Analytical results of P.C.s* in wine samples $(n=3)$.

\begin{tabular}{|c|c|c|c|c|c|c|c|c|c|c|c|c|c|c|}
\hline $\begin{array}{l}\text { Wine } \\
\text { samples }\end{array}$ & $\begin{array}{l}\text { Added } \\
(\mu g / \\
L)\end{array}$ & & CnA & pCuA & FA & SnA & CA & ChA & SyA & PrA & GA & KfI & Qcn & Res \\
\hline \multirow[t]{3}{*}{ Red } & 0 & Found & $\begin{array}{l}58.3 \pm 7 . \\
1\end{array}$ & $\begin{array}{l}255.7 \pm 0 . \\
3\end{array}$ & $\begin{array}{l}382.0 \pm 0 . \\
3\end{array}$ & ND & $2.8 \pm 0.2$ & $\begin{array}{l}108.0 \pm 0 . \\
6\end{array}$ & $\begin{array}{l}270.0 \pm 0 . \\
6\end{array}$ & $1.4 \pm 0.8$ & $\begin{array}{l}194.0 \pm 3 . \\
2\end{array}$ & $\begin{array}{l}233.012 . \\
3\end{array}$ & $\begin{array}{l}103.7 \pm 0 . \\
9\end{array}$ & $81.5 \pm 0.6$ \\
\hline & 5 & $\begin{array}{l}\text { RR,RS } \\
D(\%)\end{array}$ & $\begin{array}{l}96.7 \pm 6 . \\
13\end{array}$ & $97.6 \pm 9.7$ & $97.5 \pm 8.4$ & $75.4 \pm 7.2$ & $84.0 \pm 8.9$ & $98.9 \pm 2.4$ & $99.7 \pm 3.9$ & $91.6 \pm 7.1$ & $99.8 \pm 6.3$ & $\begin{array}{l}99.5 \pm 10 . \\
6\end{array}$ & $99.2 \pm 6.8$ & $98.9 \pm 0.2$ \\
\hline & 200 & $\begin{array}{l}\text { RR, RS } \\
D(\%)\end{array}$ & $\begin{array}{l}95.2 \pm 5 . \\
2\end{array}$ & $96.8 \pm 7.2$ & $96.4 \pm 3.3$ & $79.2 \pm 4.9$ & $87.5 \pm 1.5$ & $89.9 \pm 2.5$ & $96.8 \pm 1.0$ & $92.5 \pm 6.6$ & $90.1 \pm 5.6$ & $98.1 \pm 6.2$ & $94.3 \pm 5.4$ & $97.6 \pm 1.0$ \\
\hline \multirow[t]{3}{*}{ White } & 0 & Found & $2.9 \pm 0.7$ & $69.6 \pm 0.9$ & $85.1 \pm 0.4$ & ND & $\begin{array}{l}308 \cdot 0 \pm 1 . \\
4\end{array}$ & $7.8 \pm 2.7$ & $54.8 \pm 0.2$ & $\begin{array}{l}496.0 \pm 0 . \\
1\end{array}$ & $\begin{array}{l}491.0 \pm 4 . \\
9\end{array}$ & ND & ND & ND \\
\hline & 5 & $\begin{array}{l}R R, R S \\
D(\%)\end{array}$ & $\begin{array}{l}89.4 \pm 5 \\
3\end{array}$ & $95.18 \pm .3$ & $\begin{array}{l}99.0 \pm 12 . \\
4\end{array}$ & $75.22 \pm .8$ & $99.6 \pm 1.8$ & $86.0 \pm 9.4$ & $98.1 \pm 6.6$ & $99.9 \pm 4.0$ & $99.9 \pm 7.8$ & $\begin{array}{l}83.5 \pm 10 . \\
1\end{array}$ & $80.5 \pm 8.3$ & $80.0 \pm 4.9$ \\
\hline & 200 & $\begin{array}{l}\text { RR, RS } \\
D(\%)\end{array}$ & $\begin{array}{l}91.8 \pm 2 . \\
5\end{array}$ & $93.1 \pm 5.8$ & $91.9 \pm 1.5$ & $78.4 \pm 2.4$ & $97.4 \pm 3.8$ & $92.9 \pm 6.5$ & $93.4 \pm 1.3$ & $97.3 \pm 0.9$ & $97.3 \pm 4.0$ & $88.9 \pm 8.1$ & $88.7 \pm 5.8$ & $84.7 \pm 0.6$ \\
\hline \multirow[t]{3}{*}{$\begin{array}{l}\text { Black } \\
\text { mulberry }\end{array}$} & 0 & Found & ND & $\begin{array}{l}238.0 \pm 0 . \\
1\end{array}$ & $\begin{array}{l}301.0 \pm 0 . \\
2\end{array}$ & ND & $\begin{array}{l}415.5 \pm 2 . \\
7\end{array}$ & $\begin{array}{l}447.5 \pm 0 . \\
1\end{array}$ & $280 \pm 0.5$ & $1.6 \pm 0.4$ & $\begin{array}{l}407.0 \pm 0 . \\
8\end{array}$ & ND & $\begin{array}{l}338.0 \pm 1 \\
8\end{array}$ & ND \\
\hline & 5 & $\begin{array}{l}R R, R S \\
D(\%)\end{array}$ & $\begin{array}{l}86.4 \pm, 5 . \\
0\end{array}$ & $99.4 \pm 6.8$ & $99.6 \pm 3.1$ & $76.6 \pm 9.2$ & $96.5 \pm 5.6$ & $99.6 \pm 5.7$ & $99.5 \pm 6.6$ & $81.6 \pm 5.4$ & $99.6 \pm 2.4$ & $78.2 \pm 4.4$ & $99.5 \pm 1.1$ & $\begin{array}{l}86.2 \pm 10 . \\
2\end{array}$ \\
\hline & 200 & $\begin{array}{l}\text { RR,RS } \\
D(\%)\end{array}$ & $\begin{array}{l}92.60 \pm 0 \\
.8\end{array}$ & $93.6 \pm 0.2$ & $93.8 \pm 3.5$ & $80.9 \pm 0.9$ & $93.3 \pm 3.6$ & $95.1 \pm 1.2$ & $93.4 \pm 0.3$ & $83.7 \pm 3.2$ & $92.9 \pm 2.9$ & $89.9 \pm 2.1$ & $94.7 \pm 0.3$ & $88.8 \pm 5.4$ \\
\hline \multirow[t]{3}{*}{ Blueberry } & 0 & Found & ND & $\begin{array}{l}107.0 \pm 0 . \\
8\end{array}$ & ND & ND & $\begin{array}{l}415.5 \pm 4 . \\
5\end{array}$ & $3.7 \pm 0.5$ & ND & $1.7 \pm 0.2$ & $\begin{array}{l}416.0 \pm 2 . \\
1\end{array}$ & $\begin{array}{l}448.5 \pm 7 . \\
9\end{array}$ & $\begin{array}{l}469.0 \pm 6 . \\
7\end{array}$ & $\begin{array}{l}482.0 \pm 0 . \\
2\end{array}$ \\
\hline & 5 & $\begin{array}{l}R R, R S \\
D(\%)\end{array}$ & $\begin{array}{l}82.2 \pm 8 \\
3\end{array}$ & $88.7 \pm 8.3$ & $80.7 \pm 8.1$ & $77.6 \pm 3.1$ & $99.5 \pm 5.2$ & $82.2 \pm 6.3$ & $\begin{array}{l}80.0 \pm 10 \\
5\end{array}$ & $79.6 \pm 8.4$ & $99.6 \pm 8.2$ & $99.6 \pm 6.9$ & $99.7 \pm 7.8$ & $99.7 \pm 4.5$ \\
\hline & 200 & $\begin{array}{l}\text { RR, RS } \\
D(\%)\end{array}$ & $\begin{array}{l}88.5 \pm 4 . \\
6\end{array}$ & $86.1 \pm 5.1$ & $82.4 \pm 4.1$ & $85.1 \pm 2.3$ & $96.8 \pm 6.5$ & $91.0 \pm 4.7$ & $83.8 \pm 4.3$ & $83.2 \pm 5.2$ & $86.1 \pm 0.9$ & $86.2 \pm 5.0$ & $87.1 \pm 1.9$ & $83.0 \pm 3.5$ \\
\hline \multirow[t]{3}{*}{ Melon } & 0 & Found & ND & $\begin{array}{l}371.0 \pm 1 . \\
8\end{array}$ & $\begin{array}{l}311.0 \pm 2 . \\
0\end{array}$ & ND & $\begin{array}{l}453.0 \pm 0 . \\
1\end{array}$ & $\begin{array}{l}294.0 \pm 0 . \\
2\end{array}$ & $\begin{array}{l}272.0 \pm 4 . \\
5\end{array}$ & $\begin{array}{l}441.0 \pm 7 \\
9\end{array}$ & $\begin{array}{l}312.0 \pm 0 . \\
8\end{array}$ & ND & ND & ND \\
\hline & 5 & $\begin{array}{l}\text { RR,RS } \\
D(\%)\end{array}$ & $\begin{array}{l}81.8 \pm 4 . \\
63\end{array}$ & $99.7 \pm 1.3$ & $99.8 \pm 1.5$ & $73.4 \pm 7.7$ & $99.8 \pm 0.9$ & $99.6 \pm 1.8$ & $99.6 \pm 3.9$ & $99.9 \pm 0.6$ & $99.8 \pm 1.8$ & $84.2 \pm 4.8$ & $84.4 \pm 5.1$ & $81.6 \pm 1.4$ \\
\hline & 200 & $\begin{array}{l}\text { RR,RS } \\
D(\%)\end{array}$ & $\begin{array}{l}93.7 \pm 1 . \\
3\end{array}$ & $95.7 \pm 0.5$ & $95.9 \pm 0.8$ & $89.9 \pm 0.1$ & $96.4 \pm 0.7$ & $95.1 \pm 0.8$ & $92.4 \pm 0.7$ & $96.0 \pm 0.6$ & $91.4 \pm 0.9$ & $93.5 \pm 1.1$ & $88.5 \pm 1.2$ & $96.5 \pm 2.8$ \\
\hline \multirow[t]{3}{*}{ Red plum } & 0 & Found & ND & $\begin{array}{l}448.0 \pm 8 \\
5\end{array}$ & $\begin{array}{l}364.0 \pm 4 . \\
2\end{array}$ & ND & $\begin{array}{l}957.0 \pm 6 . \\
6\end{array}$ & $\begin{array}{l}314.0 \pm 4 . \\
2\end{array}$ & ND & ND & ND & $\begin{array}{l}398.0 \pm 8 . \\
5\end{array}$ & $\begin{array}{l}975.0 \pm 10 \\
.6\end{array}$ & ND \\
\hline & 5 & $\begin{array}{l}\text { RR } \\
\%, \text { RSD }\end{array}$ & $\begin{array}{l}84.6 \pm 4 . \\
8\end{array}$ & $99.7 \pm 1.3$ & $99.5 \pm 6.0$ & $75.2 \pm 1.4$ & $99.8 \pm 6.8$ & $\begin{array}{l}99.4 \pm 3.9 \\
6\end{array}$ & $78.8 \pm 8.4$ & $72.8 \pm 7.2$ & $77 \pm .64 .1$ & $\begin{array}{l}99 . \\
\pm 51.9\end{array}$ & $99 \pm .89 .2$ & $76.2 \pm 6.6$ \\
\hline & 200 & $\begin{array}{l}\text { RR } \\
\%, \text { RSD }\end{array}$ & $\begin{array}{l}91.0 \pm 4 . \\
4\end{array}$ & $98.3 \pm 1.4$ & $93.1 \pm 3.5$ & $85.1 \pm 4.4$ & $95.1 \pm 0.8$ & $97.4 \pm 3.0$ & $89.5 \pm 7.9$ & $83.0 \pm 3.2$ & $81.7 \pm 2.7$ & $96.6 \pm 2.2$ & $97.0 \pm 0.5$ & $93.3 \pm 4.3$ \\
\hline
\end{tabular}

${ }^{a}$ Values are mean \pm standard deviation

${ }^{\mathrm{b}} \mathrm{RR}$ : Relative recovery; ND: not detected

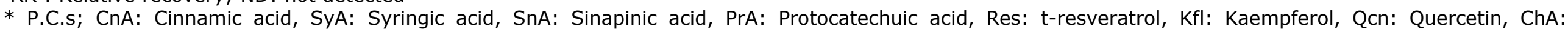

Chlorogenic acid, pCuA: p-Coumaric acid, F.A.: Ferulic acid, CA: Caffeic acid, GA: Gallic acid 
Tashakkori P, Altinisik Tagac A, Merdivan M. JOTCSA. ACKNOWLEDGMENTS

This work was supported by the Dokuz Eylul University research foundation (grant number DEU 2018.KB.FEN.033).

\section{SUPPORTING INFORMATION SUMMARY}

Details of parameters of SIM mode for P.C.S after derivatization and characterization studies of GO[APMIM][NTf2] coating material are given in the supporting information.

\section{REFERENCES}

1. Pourcel L, Routaboul J, Cheynier V, Lepiniec L, Debeaujon I. Flavonoid oxidation in plants: from biochemical properties to physiological functions. Trends in Plant Science. 2007 Jan;12(1):29-36.

2. Lesschaeve I, Noble AC. Polyphenols: factors influencing their sensory properties and their effects on food and beverage preferences. The American Journal of Clinical Nutrition. 2005 Jan $1 ; 81(1): 330$ S-335S.

3. Cardona F, Andrés-Lacueva C, Tulipani S, Tinahones FJ, Queipo-Ortuño MI. Benefits of polyphenols on gut microbiota and implications in human health. The Journal of Nutritional Biochemistry. 2013 Aug;24(8):1415-22.

4. Klatsky AL. Wine, Liquor, Beer, and Mortality. American Journal of Epidemiology. 2003 Sep 15;158(6):585-95.

5. Nave F, Cabrita MJ, da Costa CT. Use of solid-supported liquid-liquid extraction in the analysis of polyphenols in wine. Journal of Chromatography A. 2007 Oct;1169(1-2):23-30.

6. Denderz N, Lehotay J. Using of molecularly imprinted polymers for determination of gallic and protocatechuic acids in red wines by high performance liquid chromatography. Journal of Chromatography A. 2014 Dec;1372:72-80.

7. Cacho JI, Campillo N, Viñas $P$, HernándezCórdoba M. Stir bar sorptive extraction with gas chromatography-mass spectrometry for the determination of resveratrol, piceatannol and oxyresveratrol isomers in wines. Journal of Chromatography A. 2013 Nov;1315:21-7.

8. Aresta A, Cotugno P, Massari F, Zambonin C. Determination of Trans-resveratrol in Wines, Spirits, and Grape Juices Using Solid-Phase Micro Extraction Coupled to Liquid Chromatography with UV Diode-Array Detection. Food Anal Methods. 2018 Feb;11(2):426-31.

9. Arthur $\mathrm{CL}$, Pawliszyn Janusz. Solid phase microextraction with thermal desorption using fused
RESEARCH ARTICLE

$2020 ; 7(2): 411-426$.

Anal Chem. 1990 Oct;62(19):2145-8.

10. Souza-Silva ÉA, Jiang $R$, Rodríguez-Lafuente A, Gionfriddo E, Pawliszyn J. A critical review of the state of the art of solid-phase microextraction of complex matrices I. Environmental analysis. TrAC Trends in Analytical Chemistry. 2015 Sep;71:22435.

11. Dreyer DR, Park S, Bielawski CW, Ruoff RS. The chemistry of graphene oxide. Chem Soc Rev. 2010;39(1):228-40.

12. Ye N, Shi P. Applications of Graphene-Based Materials in Solid-Phase Extraction and Solid-Phase Microextraction. Separation \& Purification Reviews. 2015 Jul 3;44(3):183-98.

13. Dahaghin $Z$, Mousavi $H Z$, Sajjadi SM. Synthesis and Application of Magnetic Graphene Oxide Modified with 8-Hydroxyquinoline for Extraction and Preconcentration of Trace Heavy Metal Ions. ChemistrySelect. 2017 Jan $23 ; 2(3): 1282-9$.

14. Anderson JL, Armstrong DW, Wei G-T. Ionic Liquids in Analytical Chemistry. Anal Chem. 2006 May;78(9):2892-902.

15. Berthod A, Ruiz-Ángel MJ, Carda-Broch S. Recent advances on ionic liquid uses in separation techniques. Journal of Chromatography A. 2018 Jul;1559:2-16.

16. Hou X, Guo Y, Liang X, Wang X, Wang L, Wang $L$, et al. Bis(trifluoromethanesulfonyl)imidebased ionic liquids grafted on graphene oxidecoated solid-phase microextraction fiber for extraction and enrichment of polycyclic aromatic hydrocarbons in potatoes and phthalate esters in food-wrap. Talanta. 2016 Jun;153:392-400.

17. Li G, Ho Row K. Ionic liquid based on imidazolium cation to modify functional materials on separation of active compounds. Journal of Liquid Chromatography \& Related Technologies. 2018 Oct 2;41(15-16):937-48.

18. Tashakkori $\mathrm{P}$, Erdem $\mathrm{P}$, Merdivan $\mathrm{M}$, Bozkurt SS. Determination of Phthalate Esters in Water and Coffee by Solid-Phase Microextraction Using Vinyl Terminated Imidazolium Based Ionic Liquid Grafted on Graphene Oxide Coatings. ChemistrySelect. 2019 Feb 28;4(8):2307-13.

19. Tian Y, Gou X, Niu P, Sun L, Guo Y. Multivariate Data Analysis of the Physicochemical and Phenolic Properties of Not from Concentrate Apple Juices to Explore the Alternative Cultivars in Juice Production. Food Anal Methods. 2018 Jun;11(6): 1735-47. 
Tashakkori P, Altinisik Tagac A, Merdivan M. JOTCSA. 2020; 7(2): 411- 426.

RESEARCH ARTICLE

20. Anli E, Vural N, Demiray S, Özkan M. Transresveratrol and Other Phenolic Compounds in Turkish Red Wines with HPLC. Journal of Wine Research. 2006 Aug;17(2):117-25.

21. Viñas $P$, Campillo $N$, Hernández-Pérez $M$, Hernández-Córdoba M. A comparison of solid-phase microextraction and stir bar sorptive extraction coupled to liquid chromatography for the rapid analysis of resveratrol isomers in wines, musts and fruit juices. Analytica Chimica Acta. 2008 Mar;611(1):119-25.

22. Mirnaghi FS, Mousavi F, Rocha SM, Pawliszyn J. Automated determination of phenolic compounds in wine, berry, and grape samples using 96-blade solid phase microextraction system coupled with liquid chromatography-tandem mass spectrometry. Journal of Chromatography A. 2013 Feb; 1276:12-9.

23. Chen $L$, Huang $X$. Preparation and application of a poly (ionic liquid)-based molecularly imprinted polymer for multiple monolithic fiber solid-phase microextraction of phenolic acids in fruit juice and beer samples. Analyst. 2017;142(21):4039-47.

24. Canini A, Alesiani D, D'Arcangelo G, Tagliatesta P. Gas chromatography-mass spectrometry analysis of phenolic compounds from Carica papaya L. leaf. Journal of Food Composition and Analysis. 2007 Nov;20(7):584-90.

25. Bustamante $L$, Cárdenas $D$, von Baer $D$, Pastene E, Duran-Sandoval D, Vergara C, et al. Evaluation of microextraction by packed sorbent, liquid-liquid microextraction and derivatization pretreatment of diet-derived phenolic acids in plasma by gas chromatography with triple quadrupole mass spectrometry. J Sep Sci. 2017 Sep;40(17):3487-96.

26. Montes R, García-López M, Rodríguez I, Cela R. Mixed-mode solid-phase extraction followed by acetylation and gas chromatography mass spectrometry for the reliable determination of transresveratrol in wine samples. Analytica Chimica Acta. $2010 \mathrm{Jul} ; 673(1): 47-53$.

27. Cacho JI, Campillo N, Viñas P, HernándezCórdoba M. Stir bar sorptive extraction with gas chromatography-mass spectrometry for the determination of resveratrol, piceatannol and oxyresveratrol isomers in wines. Journal of Chromatography A. 2013 Nov;1315:21-7.
28. Viñas $P$, Campillo $N$, Martínez-Castillo $N$, Hernández-Córdoba $M$. Solid-phase microextraction on-fiber derivatization for the analysis of some polyphenols in wine and grapes using gas chromatography-mass spectrometry. Journal of Chromatography A. 2009 Feb;1216(9):1279-84.

29. Cai L, Koziel JA, Dharmadhikari M, (Hans) van Leeuwen J. Rapid determination of transresveratrol in red wine by solid-phase microextraction with on-fiber derivatization and multidimensional gas chromatography-mass spectrometry. Journal of Chromatography A. 2009 Jan;1216(2):281-7.

30. Citová I, Sladkovský R, Solich P. Analysis of phenolic acids as chloroformate derivatives using solid phase microextraction-gas chromatography. Analytica Chimica Acta. 2006 Jul;573-574:231-41.

31. Angioni A, Pintore GAM, Caboni $P$. Determination of Wine Aroma Compounds by Dehydration Followed by GC/MS. Journal of AOAC INTERNATIONAL. 2012 May 1;95(3):813-9.

32. Erdem $\mathrm{P}$, Tashakkori $\mathrm{P}$, Merdivan M, Bozkurt SS. Ionic liquid-based graphene oxide-coated fiber for headspace-solid phase microextraction of polycyclic aromatic hydrocarbons in water samples. Turkish Journal of Chemistry. 2019;43:1383-97.

33. Yang $H$, Shan $C$, Li F, Han D, Zhang Q, Niu L. Covalent functionalization of polydisperse chemically-converted graphene sheets with amineterminated ionic liquid. Chem Commun. 2009; (26): 3880 .

34. Yuan S, Liu Z, Lian $H$, Yang $C$, Lin Q, Yin $H$, et al. Simultaneous determination of eleven estrogenic and odorous chloro- and bromo-phenolic compounds in surface water through an automated online headspace SPME followed by on-fiber derivatization coupled with GC-MS. Anal Methods. 2017;9(33):4819-27.

35. Proestos C, Sereli D, Komaitis M. Determination of phenolic compounds in aromatic plants by RP-HPLC and GC-MS. Food Chemistry. 2006 Mar;95(1):44-52.

36. Xie L, Liu S, Han $Z$, Jiang $R$, Liu $H$, Zhu F, et al. Preparation and characterization of metal-organic framework MIL-101(Cr)-coated solid-phase microextraction fiber. Analytica Chimica Acta. 2015 Jan;853:303-10. 


\section{Graphene Oxide-Ionic Liquid Used as Solid-Phase Microextraction Coating for Polyphenolic Compounds' Extraction and Determination with GC-MS After On-Fiber Derivatization in Wine}

\section{Paniz Tashakkori, Aylin Altinisik Tagac, Melek Merdivan* Supporting Information}

Table S1. Parameters of SIM mode for PCs after derivatization.

\begin{tabular}{|c|c|c|c|c|c|}
\hline Compound & $\begin{array}{l}\text { Molecular } \\
\text { weight }\end{array}$ & TMS groups & $\begin{array}{l}\text { TMS derivatized } \\
\text { molecular weight }\end{array}$ & $t_{R}(\min )$ & Characteristic fragments ${ }^{[a]}$ \\
\hline Cinnamic acid & 148 & 1 & 220 & 4.48 & $131,161,205,145,220$ \\
\hline p-Coumaric acid & 164 & 2 & 308 & 6.01 & $\underline{219}, 293,245,308$ \\
\hline Ferulic acid & 194 & 2 & 338 & 8.07 & $\underline{249}, 323,338,219$ \\
\hline Syringic acid & 198 & 2 & 342 & 9.30 & $\underline{327}, 342,312,297$ \\
\hline Sinapinic acid & 224 & 2 & 368 & 11.01 & $\underline{353}, 368,338,249$ \\
\hline Protocatechuic acid & 154 & 3 & 370 & 12.13 & $\underline{193}, 370,355,73$ \\
\hline Caffeic acid & 180 & 3 & 396 & 13.04 & $\underline{291}, 396,381,73$ \\
\hline Resveratrol & 228 & 3 & 444 & 14.71 & $\underline{267}, 179,429,444$ \\
\hline Gallic acid & 170 & 4 & 458 & 15.82 & $\underline{281}, 147,179,458$ \\
\hline Kaempferol & 286 & 4 & 574 & 16.44 & $\underline{487}, 574,559,272$ \\
\hline Quercetin & 302 & 5 & 662 & 17.35 & $\underline{647}, 574,559,662$ \\
\hline Chlorogenic acid & 354 & 6 & 786 & 19.16 & $\underline{419}, 786,397,345$ \\
\hline
\end{tabular}

[a] Quantitations are underlined.

\section{Characterization of GO-[APMIM][NTf $\left.{ }_{2}\right]$ coating material}

In the FTIR study (Figure $\mathrm{S} 1(\mathrm{~A})$ ), as well as the main peaks of GO, the presence of IL was verified by the peaks at 2914, 2847, 1578 and $1456 \mathrm{~cm}^{-1}$ corresponding to the stretching vibrations of C-H in imidazole ring, aliphatic groups, $\mathrm{C}-\mathrm{N}$ and $\mathrm{C}=\mathrm{N}$ groups in imidazole ring, respectively. In thermal gravimetric analysis curves (Figure S1(B)), GO-[APMIM] $\left[\mathrm{NTf}_{2}\right]$ coating with fewer thermally labile oxygen functional groups has a mass loss in the range of $200-450^{\circ} \mathrm{C}$ at the low slope (from $95 \%$ to $70 \%$ weight loss) beside the moisture loss at $150{ }^{\circ} \mathrm{C}$. In XRD powder patterns (Figure S1(C)), the appearance of new peaks at $2 \theta=23.67^{\circ}$, $38.17^{\circ}$ and $40.51^{\circ}$ explain the exfoliation of GO due to the removing of water molecules and the oxide groups and interaction with IL. 

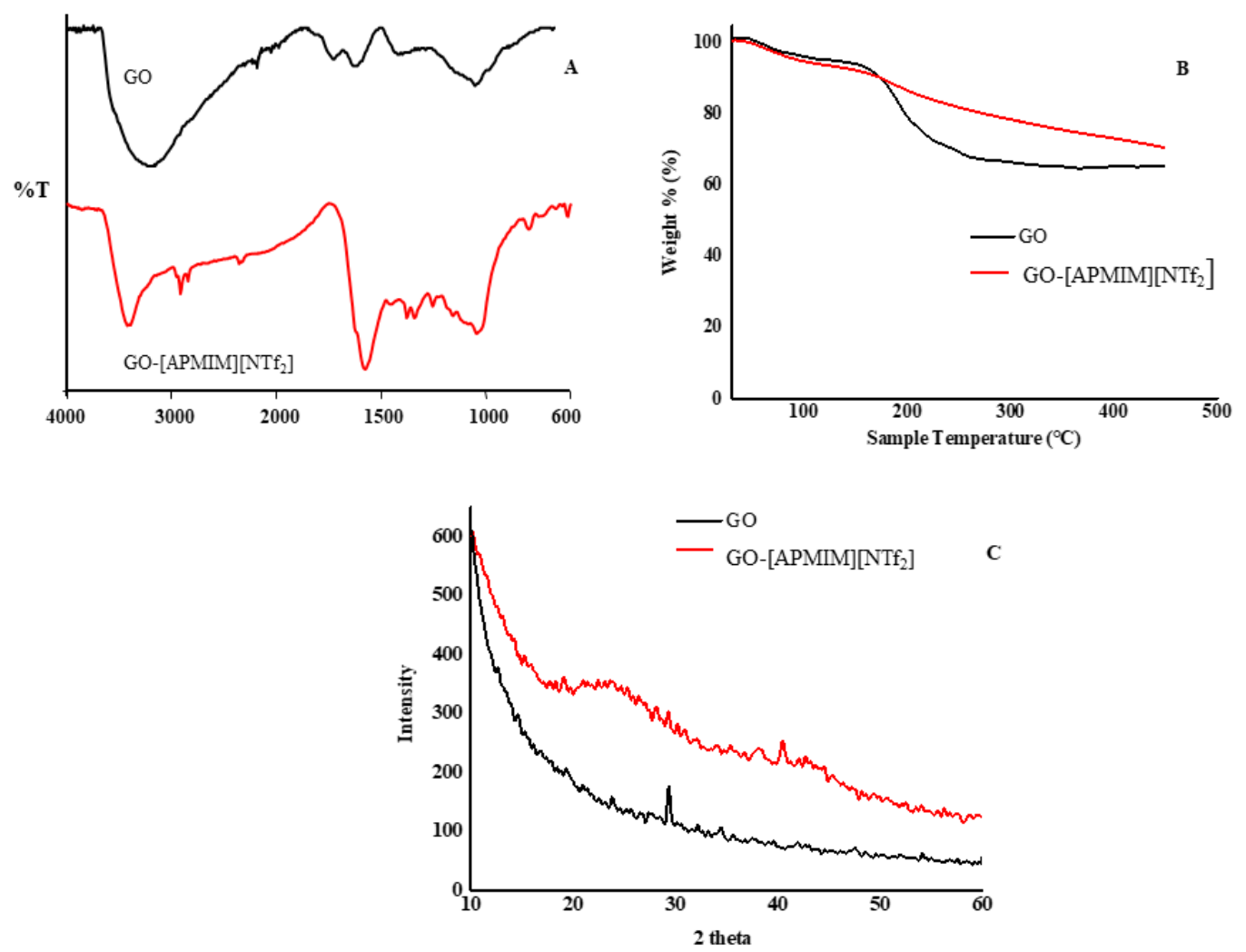

Figure S1: FTIR spectra (A), thermogravimetric analysis (B), and XRD patterns of GO and GO-[APMIM][NTf 2] (C). 
